\title{
miR-888 functions as an oncogene and predicts poor prognosis in colorectal cancer
}

\author{
SU-JUN GAO *, LEI CHEN* ${ }^{*}$, WEI LU, LI ZHANG, LU WANG and HAI-HANG ZHU \\ Digestive Department of Subei People's Hospital, Clinical College of Yangzhou University, Yangzhou 225001, P.R. China
}

Received November 17, 2016; Accepted June 6, 2017

DOI: $10.3892 / \mathrm{ol} .2018 .8461$

\begin{abstract}
MicroRNAs (miRNAs) are important regulators of tumor formation, progression and metastasis. The present study characterized a novel miRNA (miR)-888, as a potent oncomiR in human colorectal cancer (CRC). The clinicopathological investigation on 126 cases of CRC patients demonstrated that the expression level of miR-888 was significantly upregulated in tumors compared with adjacent healthy tissue, and was associated with tumor stage and histological differentiation. A Kaplan-Meier analysis and log-rank test demonstrated that CRC patients with increased miR-888 expression exhibited a decreased overall survival (OS) and disease-free survival (DFS) compared with patients with low miR-888 expression. Further univariate and multivariate analyses identified miR-888 as an independent prognostic factor for poor survival outcome in CRC patients. To determine the biological role of miR-888 in human CRC, in vitro Cell Counting kit-8, wound healing and transwell assays were performed and demonstrated that miR-888 contributed greatly to CRC cell proliferation, invasion and metastasis. Furthermore, potential targets of miR-888 were investigated using a luciferase reporter assay, followed by polymerase chain reaction and western blot analysis. The findings revealed that miR-888 directly bound to the 3'-untranslated region of mothers against decapentaplegic- 4 and thus inhibited its expression and promoted the tumor growth factor-1-induced cancer metastasis signaling. The results of the present study identified miR-888 as an oncogenic miRNA in CRC and provide a foundation for promising
\end{abstract}

Correspondence to: Professor Hai-Hang Zhu, Digestive Department of Subei People's Hospital, Clinical College of Yangzhou University, 98 West Nantong Road, Yangzhou 225001, P.R. China

E-mail: haihangzhu@sina.cn

*Contributed equally

Abbreveations: miRNA, microRNA; CRC, colorectal cancer; OS, overall survival; DFS, disease-free survival; 3'-UTR, 3'-untranslated region; EMT, epithelial-mesenchymal transition; AJCC, American Joint Committee on Cancer

Key words: miR-888, colorectal cancer, prognosis, Smad4, metastasis, epithelial-mesenchymal transition research in the future regarding this predictive and prognostic biomarker.

\section{Introduction}

Colorectal cancer (CRC) is currently the third most common malignancy and the fourth leading cause of cancer-related death worldwide, with an estimated 1.2 million new cases and over 6 hundred thousand deaths each year (1). CRC develops as a result of the pathological transformation of normal colonic epithelium to adenomatous polyp, which ultimately leads to invasive cancer (2). Though the five-year survival rate of patients with resectable CRC has recently improved, exceeding $90 \%$, that of CRC patients with unresectable metastases remains discouraging at less than $10 \%$ (3). Notably, $50-60 \%$ of CRC patients can develop distant metastases and the five-year survival rate will decrease to only $5 \%$ in patients with distant metastases (4). Therefore, early diagnosis and therapy holds a significant prognostic value, and it is an urgent necessity to identify new biomarkers as well as specific therapeutic targets for CRC $(5,6)$. Tumor metastasis consists of multiple sequential biological processes, including the invasion of cancer cells into surrounding tissues, intravasation, survival in circulation, arrest at distant organ sites, extravasation, and finally growth in distant organs (7). However, despite considerable advances have been made concerning the molecular mechanisms underlying tumor metastasis, it is still far from well understood.

MicroRNAs (miRNAs) belong to a class of small endogenous RNAs that do not encode for proteins and yet influence many physiological processes through binding to the 3'-untranslated region (3'-UTR) of target messenger RNAs (mRNAs), mediating either mRNA degradation or translational repression (8). The role of miRNAs in human malignancies has been intensively studied in recent years. Dysregulated expressions of miRNAs are associated with tumor initiation, promotion and progression by acting on various oncogenes or tumor suppressors (9-11). Moreover, miRNAs have been demonstrated to be closely correlated with clinical stage, metastasis and survival in numerous human cancers, including CRC (12). microRNA-888 (miR-888), a newly identified miRNA, was reported to be implicated in the tumorigenic process of endometrial cancer, prostate cancer, and breast cancer (13-16). Lewis et al found that overexpression of miR-888 significantly increases the proliferation and migration of prostate cancer cells (14), and Huang et al showed that miR-888 is a repressor 
of the adherens junction pathway in breast cancer (15). What's more, evidences have even pointed to the involvement of miR-888 in maintaining cancer stem cell-related properties and regulating the epithelial-mesenchymal transition (EMT) and cancer metastasis (17). Nevertheless, little is known about the roles of miR-888 in the clinical pathological correlations and biological functions in CRC tumorigenesis. Thus, in the present study, we sought to determine the biological and clinicopathological implications of miR-888 in the development and metastasis of CRC.

\section{Materials and methods}

Human samples and cell lines. A total of 126 CRC patients that received surgery resection in Subei People's Hospital of Jiangsu Province between 2009 and 2014 were enrolled in this study. None of them had undergone chemotherapy, radiotherapy or immunotherapy before. Pathological analyses were used to confirm the diagnosis, and the patients were staged according to the tumor-node-metastasis (TNM) staging system of American Joint Committee on Cancer (AJCC). Detailed clinical informations of the patients are shown in Tables I and II. Tumor tissues and the paired normal tissues were obtained after surgical resection and immediately placed in liquid nitrogen or $10 \%$ formalin for further analyses. The present study was approved by the Ethics Committee of Subei People's Hospital of Jiangsu Province and written informed consent was obtained from all of the patients. The overall survival (OS) time was defined as the date of surgery to the date of death from any cause, or to the last follow-up date; while the disease-free survival (DFS) was computed from the operation date to the date of local or distant recurrence or death from any cause.

Human HEK 293 cell and colorectal cancer cell line SW620 were obtained from the American Type Culture Collection (ATCC). Cells were maintained in a humidified $5 \% \mathrm{CO}_{2}$ atmosphere at $37^{\circ} \mathrm{C}$ and were grown in complete growth medium (Invitrogen, Carlsbad, CA) as recommended by the manufacturer. Cells were regularly authenticated by checking their morphology and confirming the absence of mycoplasma contamination (MycoAlert, Lonza, Rockland, ME).

In situ hybridization and staining assessment. In situ hybridization (ISH) was performed using double-digoxigenin (DIG) labeled 2'O-methyl locked nucleic acid (LNA)-ZEN probes (Integrated DNA Technologies) complimentary to miR-888 (5'-DIG-U/ZEN/GACUGACAGCUTUUUGAG U/ZEN/A-DIG-3') along with a scrambled negative control probe (5'-DIG-C/ZEN/GUAUUAUAGCCGAUUAAC G/ZEN/A-DIG-3'), where LNA modifications are underlined. Hybridization, washing, and scanning were carried out according to previous reports (18).

The staining index (SI), a semiquantitative evaluation system incorporating the intensity and percentage of positive cells, was conducted to assess the miR-888 staining results (19). The staining intensity was classified into four grades: 0 , no staining; 1, weak; 2, moderate; 3 , strong. The percentage of cells stained was graded as follows: 0 , no staining; $1,<10 \%$; $2,10-50 \%$; and $3,>50 \%$ tumor cells. SI was calculated by multiplying the grade for percentage staining by the grade for intensity. Each sample was evaluated by two experienced pathologists in a blind manner. Scores of 4 or greater were defined as positive staining and high expression.

RNA isolation and quantitative real-time RT-PCR. RNA samples were isolated using Trizol reagent (Invitrogen) according to the manufacturer's instructions. miR-888 expression was quantified by two-step quantitative RT-PCR, beginning with first-strand cDNA synthesis using the One-step primeScript miRNA cDNA Synthesis kit, followed by quantitative real-time PCR amplification using the miRscript SYBR-Green PCR kit (Takara); while the quantitative SYBR-Green PCR kit (Qiagen, Hilden, Germany) was used to quantify the mRNA level of genes in Smad4 pathway. All primers used are shown in Table III. miRNA quantity was normalized using the small nuclear RNA U6 while the other genes were normalized to GAPDH. Fold change of miRNA/mRNA expression was calculated using the $2^{-\Delta \Delta c q}$ method.

Western blotting. Western blot analysis was performed as described previously (20), using the Smad4 antibodies (1:5000 dilution; Abcam, UK) and $\beta$-actin antibodies (1:5000 dilution; Abcam).

Vector construction and cell transfection. The miR-888 expression plasmid was generated by cloning the genomic pre-miR-888 (5'-UACUCAAAAAGCUGUCAGUCA-3') into OriGene's pCMV6-Mir Vector (Promega, Madison, WI, USA) to generate the plasmid pCMV-miR-888. The empty vector was used as a negative control (NC).

Vectors were transfected into cells with Lipofectamine 2000 (Invitrogen). The day before transfection, the cells were seeded in 6-well plates and reached a confluence of approximately $80 \%$. For each transfection experiment, $2 \mu \mathrm{g}$ of DNA and $6 \mu \mathrm{l}$ of Lipofectamine 2000 were added to $100 \mu \mathrm{l}$ of Opti-MEM medium. Medium was replaced $6 \mathrm{~h}$ later. After a $72 \mathrm{~h}$ incubation, cells were harvested for further experiments.

Luciferase reporter assay. Luciferase constructs were generated by ligating oligonucleotides containing the wild-type or mutant putative target site of the Smad4 3'-UTR into the Psi-CHECK2 vector (Promega) downstream of the luciferase gene. HEK 293 or human CRC cells were transfected with miR-888 or the NC in combination with each individual psiCHECK2 luciferase vector. Cells were collected at $24 \mathrm{~h}$ post-transfection, and Firefly and Renilla luciferase activities were measured using the Dual Luciferase Assay System (Promega) according to the manufacturer's protocol.

Cell proliferation assay. The cells were plated in 96-well plates at $5 \times 10^{3}$ cells/well and allowed to grow for 24-72 h. Subsequently, the cells were incubated with $10 \mu \mathrm{l} \mathrm{CCK}-8$ (Beyotime, Shanghai, China) at $37^{\circ} \mathrm{C}$ for $4 \mathrm{~h}$. Absorbance was measured at $450 \mathrm{~nm}$ using a microplate reader.

Wound healing assay. Cells were seeded in 6-well plates and incubated under permissive conditions until approximately $90 \%$ confluence. After serum starvation for $24 \mathrm{~h}$, wounds were created in the confluent cells using a pipette tip. Wound healing within the scrape line was then observed and photographed at 
Table I. Correlation between clinicopathological parameters and miR-888 expression in patients with colorectal cancer.

\begin{tabular}{|c|c|c|c|c|}
\hline \multirow[b]{2}{*}{ Characteristics } & \multirow[b]{2}{*}{ No. $(\%)$} & \multicolumn{2}{|c|}{ miR-888 expression } & \multirow[b]{2}{*}{$\mathrm{P}^{\mathrm{a}}$} \\
\hline & & High $n=93(\%)$ & Low $n=33(\%)$ & \\
\hline Age & & & & 0.453 \\
\hline$<60$ & $60(47.6)$ & $44(47.3)$ & $16(48.5)$ & \\
\hline$\geq 60$ & $66(52.4)$ & $49(52.7)$ & $17(51.5)$ & \\
\hline Sex & & & & 0.251 \\
\hline Male & $71(56.3)$ & $53(57.0)$ & $18(54.5)$ & \\
\hline Female & $55(43.7)$ & $40(43.0)$ & $15(45.5)$ & \\
\hline Tumor location & & & & 0.235 \\
\hline Left & $79(62.7)$ & $59(63.4)$ & $20(60.6)$ & \\
\hline Transverse & $13(10.3)$ & $9(9.7)$ & $4(12.1)$ & \\
\hline Right & $34(27.0)$ & $25(26.9)$ & $9(27.3)$ & \\
\hline pT status & & & & $0.009^{\mathrm{a}}$ \\
\hline $\mathrm{T} 1 / \mathrm{T} 2$ & $28(22.2)$ & $14(15.1)$ & $14(42.4)$ & \\
\hline $\mathrm{T} 3 / \mathrm{T} 4$ & $98(77.8)$ & $79(84.9)$ & $19(57.6)$ & \\
\hline pN status & & & & $0.031^{\mathrm{a}}$ \\
\hline Absent & $72(57.1)$ & 48 (51.6) & $24(72.7)$ & \\
\hline Present & $54(42.9)$ & $45(48.4)$ & $9(27.3)$ & \\
\hline pMstatus & & & & $0.018^{\mathrm{a}}$ \\
\hline Absent & $116(92.1)$ & $84(90.3)$ & $32(97.0)$ & \\
\hline Present & $10(7.9)$ & $9(9.7)$ & $1(3.0)$ & \\
\hline AJCC stage & & & & $0.042^{\mathrm{a}}$ \\
\hline $\mathrm{I} / \mathrm{II}$ & $71(56.3)$ & $48(51.6)$ & $23(69.7)$ & \\
\hline III/IV & $55(43.7)$ & $45(48.4)$ & $10(30.3)$ & \\
\hline Differentiation & & & & $0.005^{\mathrm{a}}$ \\
\hline Well & $27(21.4)$ & $13(14.0)$ & $14(42.4)$ & \\
\hline Moderate & 78 (61.9) & $60(64.5)$ & $18(54.5)$ & \\
\hline Poor & $21(16.7)$ & $20(21.5)$ & $1(3.0)$ & \\
\hline
\end{tabular}



indicated time points. Each experiment was repeated at least three times.

Transwell invasion assay. A Boyden chamber with $8 \mu \mathrm{m}$-pore filter membrane was used. Briefly, cells $\left(1 \times 10^{5}\right)$ in culture medium containing free FBS were seeded in the upper chamber, and the culture medium with $20 \%$ FBS was added in the lower chamber as a chemoattractant. The upper side of the filter was coated with 0.2\% Matrigel (BD Biosciences, San Jose, CA, USA). After incubation for $48 \mathrm{~h}$, the cells on the upper side of the filter were removed with cotton swabs, while the cells that migrated to the lower side were fixed in $4 \%$ paraformaldehyde and stained with crystal violet. The cells invaded to the lower surface of the filter were counted at 10 random fields.

Statistical analysis. All statistical analyses were carried out using the SPSS v20.0 program. Data were expressed as mean \pm standard deviation (SD). The two-tailed paired Student's t-test was conducted for analyzing two groups.
Group differences were statistically analyzed using the $\chi^{2}$ test. Survival curves were described by the Kaplan-Meier method and compared with the log-rank test. Prognostic factors and survival data were evaluated using univariate and multivariate Cox regression analyses. $\mathrm{P}<0.05$ was considered to indicate a statistically significant difference.

\section{Results}

High level of miR-888 expression is correlated with aggressive $C R C$. To determine the clinical and pathological relevance of miR-888 in human CRC, we explored the expression of miR-888 in 126 cases of primary CRC biopsies by qRT-PCR and found that the miR-888 expression level was significantly upregulated in tumor tissues compared with the paired adjacent normal tissues (Fig. 1A). Furthermore, patients with distant metastatic tumors showed a remarkably higher miR-888 level than those without tumor metastasis. The level of miR-888 in metastatic tumors was 2.9-fold higher than that in non-metastatic tumors (Fig. 1B). Further in situ 


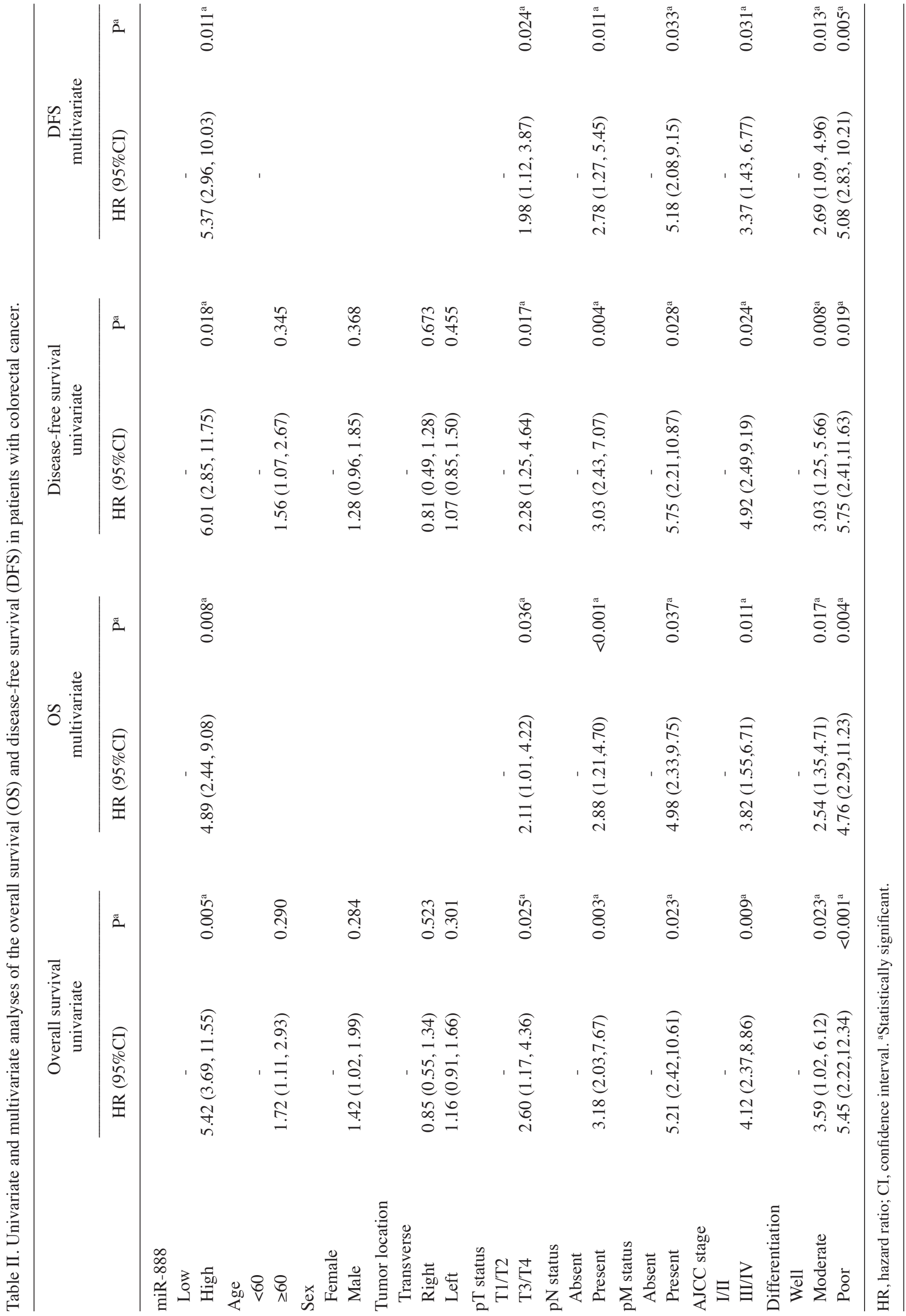


Table III. Primers used in this study.

\begin{tabular}{ll}
\hline Oligo & \multicolumn{1}{c}{ Sequence } \\
\hline $\begin{array}{l}\text { Smad4 } \\
\text { (Foward) }\end{array}$ & 5'-CGGACATTACTGGCCTGTTC-3' \\
$\begin{array}{l}\text { Smad4 } \\
\text { (Reverse) }\end{array}$ & 5'-TAGGGCAGCTTGAAGGAAACC-3' \\
$\begin{array}{l}\text { E-cadherin } \\
\text { (Forward) }\end{array}$ & 5'-GAAGTGTCCGAGGACTTTGG-3' \\
$\begin{array}{l}\text { E-cadherin } \\
\text { Reverse) }\end{array}$ & 5'-CAGTGTCTCTCCAAATCCGATA-3' \\
$\begin{array}{l}\text { TGF- } \beta 1 \\
\text { (Forward) }\end{array}$ & 5'-GAGGCGGTGCTCGCTTTGTA-3' \\
$\begin{array}{l}\text { TGF- } \beta 1 \\
\text { (Reverse) }\end{array}$ & 5'-GCACTGCTTCCCGAATGTCTG-3' \\
$\begin{array}{l}\text { Snail } \\
\text { (Forward) }\end{array}$ & 5'-GTCCTTGCTCCACAAACACCA-3' \\
$\begin{array}{l}\text { Snail } \\
\text { (Reverse) }\end{array}$ & 5'-CTGCCTTCCATCAGCCATCT-3' \\
$\begin{array}{l}\text { Twist } \\
\text { (Forward) } \\
\text { Twist } \\
\text { (Reverse) }\end{array}$ & 5'-GTCCGCAGTCTTACGAGGAG-3' \\
$\begin{array}{l}\text { N-cadherin } \\
\text { (Forward) }\end{array}$ & 5'-CCAGCTTGAGGGTCTGAATC-3' \\
$\begin{array}{l}\text { N-cadherin } \\
\text { Reverse) }\end{array}$ & 5'-CTGGGGTCAGAGGTGTATCATTT-3' \\
$\begin{array}{l}\text { GAPDH } \\
\text { (Forward) }\end{array}$ & 5'-ACAGTCAGCCGCATCTTCTT-3' \\
$\begin{array}{l}\text { GAPDH } \\
\text { (Reverse) } \\
\text { miR-888 } \\
\text { (Forward) } \\
\text { miR-888 } \\
\text { (Reverse) }\end{array}$ & 5'-ACTGGGGGGTTTGACTTCGTAGCCCTT-3' \\
U6 (Forward) & 5'-CTGCTTCGGCAGCACA-3' \\
U6 (Reverse) & 5'-AACGCTTCACGAATTTGCGT-3' \\
\hline
\end{tabular}

hybridization (ISH) analysis demonstrated that high miR-888 expression was detected in 93/126 (73.8\%) cases of CRC patients, whereas low miR-888 expression was observed in $33 / 126$ (26.2\%) of the patients (Fig. 1C). Clinicopathological investigations confirmed that increased miR-888 expression was positively associated with $\mathrm{pT}$ status $(\mathrm{P}=0.009), \mathrm{pN}$ status $(\mathrm{P}=0.031)$, $\mathrm{pM}$ status $(\mathrm{P}=0.018)$, AJCC stage $(\mathrm{P}=0.042)$, and histological differentiation $(\mathrm{P}=0.005)$ of tumors, but not with patients' age $(\mathrm{P}=0.453)$, sex $(\mathrm{P}=0.251)$, or tumor location $(\mathrm{P}=0.235)$ (Table I). These results indicate that miR-888 plays an important role in the progression and metastasis of CRC and represents a potential predictive marker.

Increased miR-888 expression predicts poor prognosis in patients with $C R C$. Kaplan-Meier analysis and the log-rank test were used to determine the prognostic significance of miR-888 in CRC. It was observed that patients with high miR-888 expression presented significantly shorter OS $(\mathrm{P}=0.025$, Fig. $2 \mathrm{~A})$ and
DFS ( $\mathrm{P}=0.021$, Fig. $2 \mathrm{~B})$ times than those with low miR-888 expression. Subsequently, univariate and multivariate analyses were performed to identify the risk factors correlated with the prognosis of CRC patients. The univariate Cox proportional hazard analysis showed that high miR-888 expression, advanced $\mathrm{pT}, \mathrm{N}$, and $\mathrm{M}$ status, and poor histological differentiation contributed significantly to poor OS and DFS rates in patients with CRC (Table II, $\mathrm{P}<0.05$ for all). Furthermore, after adjusting for all clinicopathological factors, multivariate analysis confirmed that miR-888 expression, the TNM stage, and histological grade were independent prognostic factors for survival (Table II, $\mathrm{P}<0.05$ for all). These above findings strongly suggest that miR-888 may serve as a predictor of poor survival among CRC patients.

miR-888 contributes to proliferation, invasion, and metastasis of CRC cells. To explore the biological role of miR-888 in CRC, miR-888 expression vectors and the empty control vectors were constructed and transfected into targeted cells. RT-PCR analysis validated that the miR-888 level was increased by 2.3 -fold in HEK 293 cells and approximately 2-fold in SW620 cells after transfection of expression vectors (Fig. 3A). We then investigated the effects of miR-888 on CRC cell proliferation by CCK- 8 assay. Overexpressing miR-888 in SW620 cells markedly upregulated the proliferation rate of cancer cells in vitro, whereas transfection of empty controls showed no significant effects on cell proliferation (Fig. 3B). We next examined the influence of miR-888 on cell migration and invasion by the wound healing assay and the transwell assay, respectively. It was found that CRC cells transfected with miR-888 expression vectors showed significantly enhanced capability of migration and invasion than those transfected with empty controls (Fig. 3C and D). Taken together, these results suggest that miR-888 may function as an oncogenic miRNA in CRC tumorigenesis.

miR-888 inhibits Smad4 expression in CRC cells by directly binding to its 3'-UTR. After reviewing the published literature and searching the miRNA prediction databases, we identified a putative miR-888 binding site in the 3'-UTR of Smad4, a well-established tumor suppressor whose mutation or loss of function causes an acceleration of tumor progression in a variety of human malignancies $(21,22)$. We thus cloned the wild-type or mutant Smad4 3'-UTR, and inserted it into a luciferase reporter vector (Fig. 4A). Our experiments showed that overexpressing miR-888 remarkably reduced the luciferase activity of the wild-type 3'-UTR of Smad4, but not the mutant reporter constructs, in both HEK 293 cells and SW620 cells (Fig. 4B and C). Further PCR and western blot verifications confirmed the direct inhibition of miR-888 on the gene and protein levels of Smad4 expression (Fig. 4D and E).

Thereafter, we investigated the expression of key factors involved in the molecular signaling of Smad4-regulated epithelial-mesenchymal transition (EMT) and tumor metastasis. PCR analysis showed that by upregulation of miR-888, the expression levels of TGF- $\beta 1$, Snail, Twist and N-cadherin in SW620 cells were significantly increased, compared with that in cells transfected with empty vectors; but in contrast, the expression level of E-cadherin was decreased (Fig. 4F). These results demonstrate the importance of miR-888-mediated 

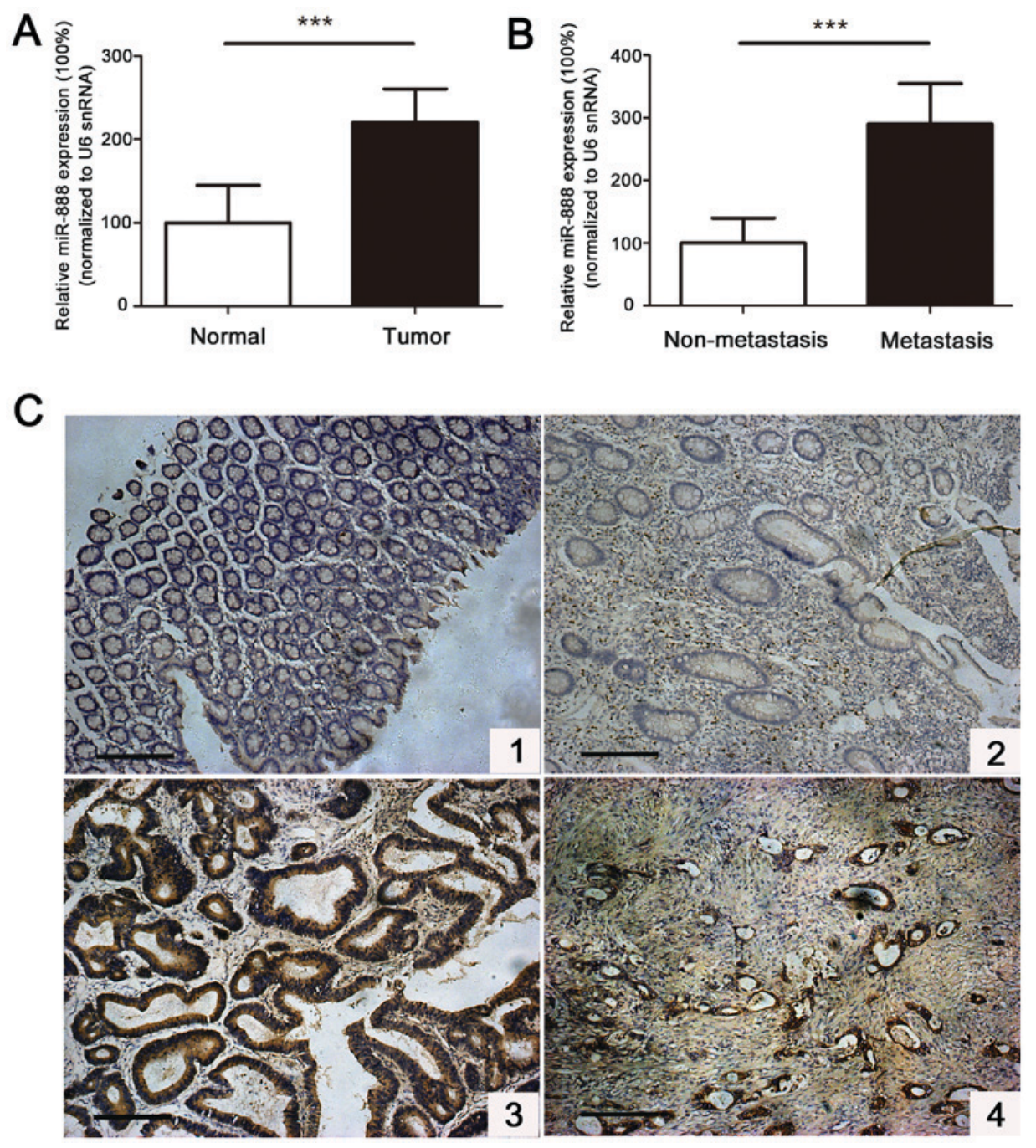

Figure 1. miR-888 expression is increased in human colorectal cancer (CRC) tissues and is closely correlated with patients' clinicopathological factors. (A) RT-PCR analysis revealed that the level of miR- 888 was increased in tumor tissues compared with the adjacent normal tissues. (B) miR-888 expression was significantly higher in metastatic tumors than in non-metastatic tumors. ${ }^{*} \mathrm{P}<0.05,{ }^{* * * *} \mathrm{P}<0.001$. Data are expressed as mean $\pm \mathrm{SD}$. (C) In situ hybridization (ISH) analysis of miR-888 expression in 126 cases of CRC and normal colon tissues. Representative images of miR-888 low expression in normal colon tissues (1) and well-differentiated CRC tissues (2); and miR-888 high expression in moderately-differentiated (3) and poorly-differentiated (4) CRC tissues. Scale bar, $100 \mu \mathrm{m}$.
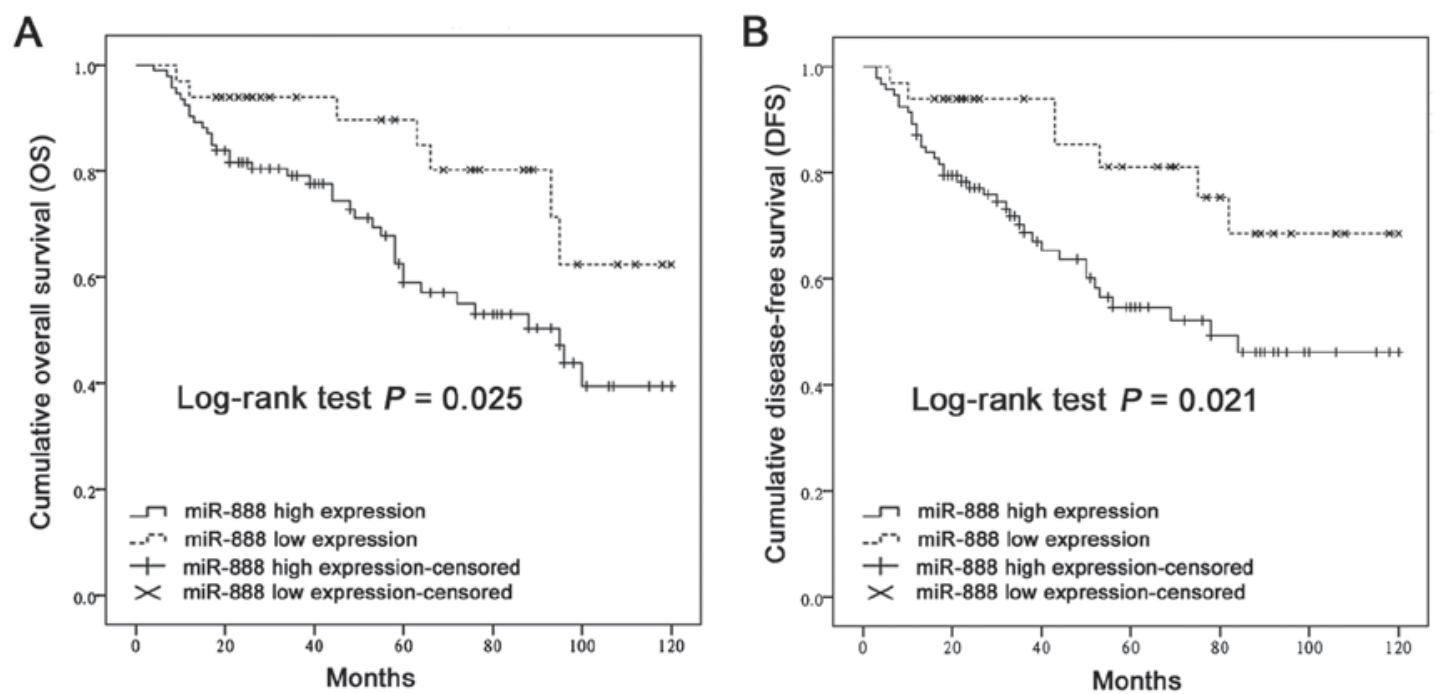

Figure 2. Kaplan-Meier survival analysis and log-rank $t$ test for colorectal cancer (CRC) patients with high/low expressions of miR-888. (A) The overall survival (OS) rates of CRC patients with low/high Bmal expression. (B) The disease-free survival (DFS) rates of patients with low/high Bmall expression. $\mathrm{P}<0.05$ was considered to indicate a statistically significant difference. 


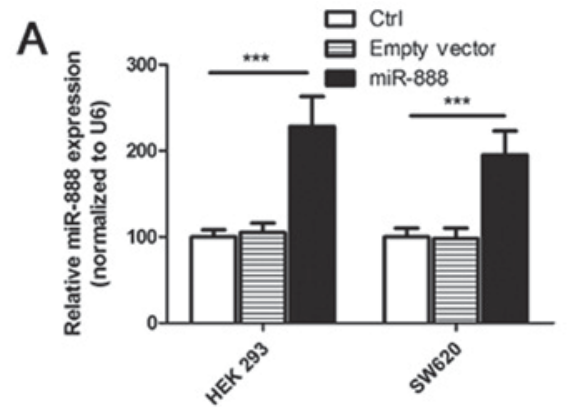

C



$\mathrm{miR}-888$

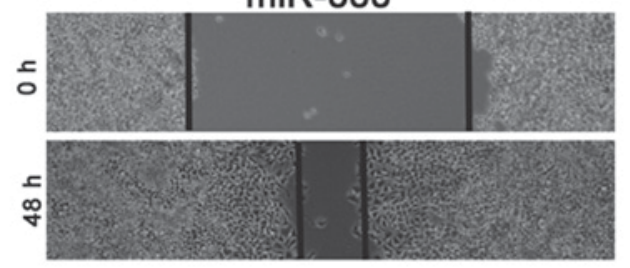

D

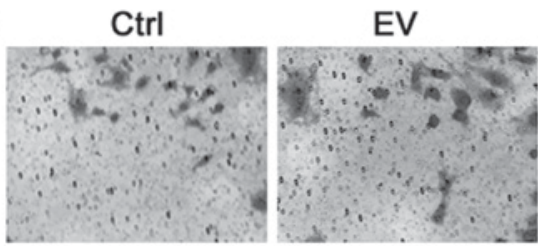

B

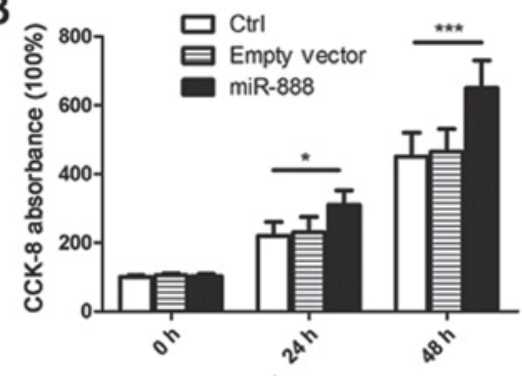

EV

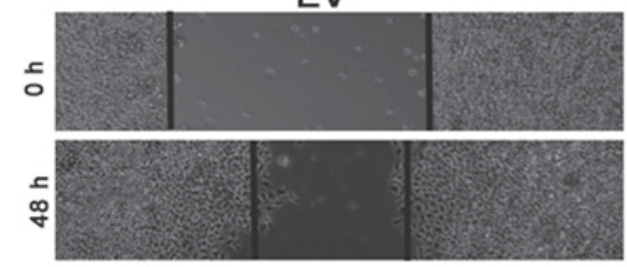

$\star \star \star \star ~$

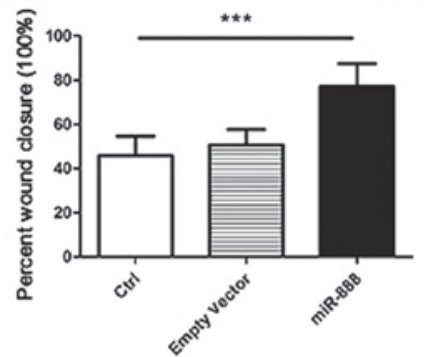

miR-888
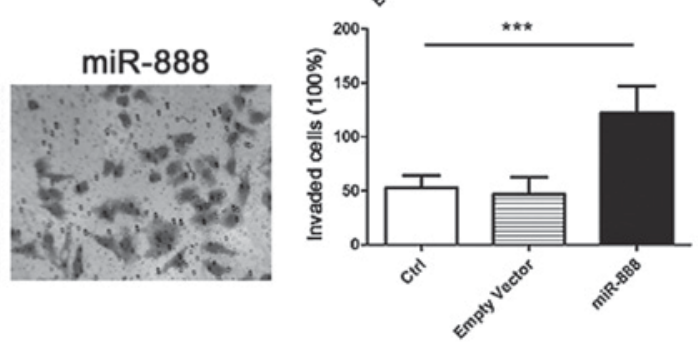

Figure 3. miR-888 promotes proliferation, migration, and invasion of colorectal cancer (CRC) cells in vitro. (A) RT-PCR verification of the transfection efficiencies of miR-888 in human HEK 293 cells and SW620 cells. U6 snRNA was used as an internal control. (B) CCK-8 analysis of cell proliferation in control SW620 cells and cells transfected with miR-888 expression vectors or the empty controls. (C) Wound healing analysis of SW620 cell migration. (D) Transwell analysis of SW620 cell invasion. Original magnification, $\mathrm{x} 200 .{ }^{*} \mathrm{P}<0.05,{ }^{* * * *} \mathrm{P}<0.001$. All data are presented as mean \pm standard deviation.

Smad4 inhibition in the regulation of CRC invasion and metastasis.

\section{Discussion}

CRC remains one of the major lethal causes of patients with cancer. Early diagnosis is an effective means to reduce the mortality of CRC patients, and the detection of biomarkers is an important component of diagnosis, as well as treatment $(23,24)$. An ideal biomarker for diagnosis should be highly specific, sensitive, and noninvasive (25). Evidences have revealed that miRNAs exhibit unique expression profiles in different tumor types and are important in the initiation and progression of human cancers (26). The crucial functions of miRNAs in carcinogenesis have promoted intensive research into miRNA-based diagnostic and therapeutic strategies for the treatment of cancer. In this study, for the first time, we characterized miR-888 as a novel colorectal cancer-associated miRNA that correlates with disease status and shares functional features of an oncogenic factor in human CRC. By systematic clinicopathological investigations, we found that miR-888 expressed significantly higher in CRC tissues than in normal colon tissues. Increased miR-888 expression was positively associated with advanced TNM stage and poor histological differentiation of tumors. We also showed that CRC patients with low miR-888 expression experienced better overall survival as well as disease-free survival outcomes; while patients with high miR-888 expression demonstrated significantly reduced survival rates. Further univariate and multivariate analyses identified miR-888 upregulation as an independent prognostic factor for survival in patients with CRC. All these findings provide strong evidence for the translational potential of miR-888 in the prediction and diagnosis of human CRC.

Recent studies have highlighted the pivotal role of miRNAs in a broad range of developmental processes associated with tumor progression and metastasis, which are controlled by complex and multistep genetic and/or epigenetic changes (27). The TGF- $\beta$ signaling has been reported to play a bilateral role in tumor development depending on the condition of the Smad 


\section{A Smad4 Wild-type 3'-UTR \\ Has-miR-888 \\ Smad4 Mutant 3'-UTR}

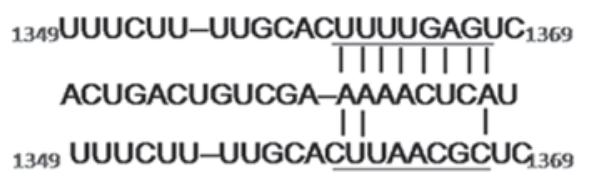

B

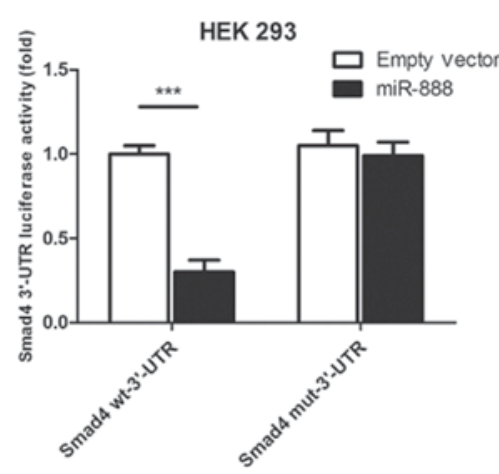

E

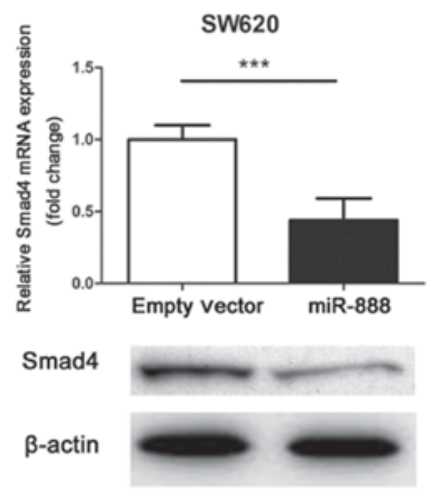

C



D



Smad4

$\beta$-actin

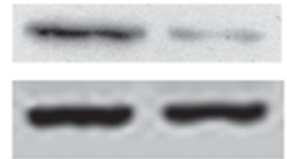



Figure 4. miR-888 directly targets the Smad4 3'-UTR and regulates the TGF- $\beta 1 /$ Smad-mediated epithelial-mesenchymal transition (EMT) signaling. (A) The complementary sequences between the position 1349-1369 of the wild-type or mutant human Smad4 3'-UTR and miR-888. (B and C) Dual luciferase reporter analysis showed the direct binding of miR-888 on Smad4 3'-UTR. HEK 293 cells (B) and SW620 cells (C) were respectively co-transfected with miR-888 or empty controls and the luciferase reporter construct containing the wild-type or mutant Smad4 3'-UTR. For each experiment, the results were normalized to the luciferase activity detected in the cells transfected with the empty vectors. ${ }^{* * *} \mathrm{P}<0.001$. (D, E) RT-PCR and western blot analyses of the effects of miR-888 on Smad4 expression in HEK 293 cells (D) and SW620 cells (E). GAPDH and $\beta$-actin were respectively used as internal controls for PCR analysis and western blotting. ${ }^{* * *} \mathrm{P}<0.001$. (F) Effects of miR-888 on the expression of key factors in the TGF- $\beta 1$-mediated EMT signaling pathway. ${ }^{* *} \mathrm{P}<0.01,{ }^{* * * *} \mathrm{P}<0.001$. All data are expressed as mean \pm standard deviation.

family proteins (28-30). Smad4, a key signal transducer of the TGF- $\beta /$ Smad pathway, generally acts as a tumor suppressor in CRC (31). It has been documented that Smad4 mutations are observed in approximately $10 \%$ of sporadic CRC patients. Loss of the functional Smad4 protein occurs frequently in the adenoma-to-carcinoma sequence, and contributes to distant metastasis, non-response to chemotherapy, and undesirable prognosis (32). In our present study, we identified miR-888 as a novel miRNA that directly binds to the 3'-UTR of Smad4 in CRC cells and causes its downregulation. By targeting the Smad4 signaling, miR-888 significantly promoted the proliferation, migration, invasion and metastasis of CRC cells. Thus, we first characterized miR- 888 as an important oncomiR in human CRC. However, given that the off-target effects, which derived from non-specific binding of miRNAs to target sequences sharing high homologies, are frequently existed when performing miRNA-related gene-silencing experiments and could possibly cause confusion on the mechanism by which the target gene is regulated $(33,34)$, microarray analysis should be used to further validate the specificity of miR-888-mediated Smad4 silencing in the future.

EMT has been validated an important step involved in cancer invasion and metastasis. During the EMT process, cells lose the epithelial characteristics, gaining instead an invasive and migratory mesenchymal phenotype, which permits these cells to leave the tissue parenchyma and enter the systemic circulations $(35,36)$. TGF- $\beta 1$ is a well-established metastatic inducer by interacting with Smad2/3/4 and promoting EMT in late-stage tumor progression (37-39). Here we demonstrated that miR-888 was capable of inducing the upregulation of the mesenchyme cell marker $\mathrm{N}$-cadherin and the intracellular transcription factors Snail and Twist; whereas the downregulation 
of the epithelial marker E-cadherin. Our findings confirmed that miR-888 is important for TGF- $\beta 1$-mediated induction of EMT and that targeting miR-888 might be an effective strategy to inhibit or reverse CRC metastasis.

In conclusion, the current study showed that miR-888 acts as an oncogenic miRNA in CRC by targeting Smad4 and represents a promising predictive and prognostic factor for CRC patients. Thus, interrupting or inhibiting miR-888 expression may provide a therapeutic approach for CRC treatment.

\section{References}

1. Torre LA, Bray F, Siegel RL, Ferlay J, Lortet-Tieulent J and Jemal A: Global cancer statistics, 2012. CA Cancer J Clin 65: 87-108, 2015

2. Verma AM, Patel M, Aslam MI, Jameson J, Pringle JH, Wurm P and Singh B: Circulating plasma microRNAs as a screening method for detection of colorectal adenomas. Lancet 385 (Suppl 1): S100, 2015.

3. Lan YT, Yang SH, Chang SC, Liang WY, Li AF, Wang HS, Jiang JK, Chen WS, Lin TC and Lin JK: Analysis of the seventh edition of American Joint Committee on colon cancer staging. Int J Colorectal Dis 27: 657-663, 2012.

4. Van Cutsem E, Cervantes A, Nordlinger B and Arnold D; ESMO Guidelines Working Group: Metastatic colorectal cancer: ESMO Clinical Practice Guidelines for diagnosis, treatment and follow-up. Ann Oncol 25 (Suppl 3): iii1-9, 2014.

5. De Rosa M, Rega D, Costabile V, Duraturo F, Niglio A, Izzo P, Pace U and Delrio P: The biological complexity of colorectal cancer: Insights into biomarkers for early detection and personalized care. Therap Adv Gastroenterol 9: 861-886, 2016.

6. Aghagolzadeh P and Radpour R: New trends in molecular and cellular biomarker discovery for colorectal cancer. World J Gastroenterol 22: 5678-5693, 2016.

7. Guan X: Cancer metastases: Challenges and opportunities. Acta Pharm Sin B 5: 402-418, 2015.

8. Ambros V: The functions of animal microRNAs. Nature 431: 350-355, 2004.

9. Svoronos AA, Engelman DM and Slack FJ: OncomiR or tumor suppressor? The duplicity of microRNAs in cancer. Cancer Res 76: 3666-3670, 2016.

10. Shah MY, Ferrajoli A, Sood AK, Lopez-Berestein G and Calin GA: microRNA therapeutics in cancer-an emerging concept. EBioMedicine 12: 34-42, 2016.

11. Behbahani GD, Ghahhari NM, Javidi MA, Molan AF, Feizi N and Babashah S: MicroRNA-mediated post-transcriptional regulation of epithelial to mesenchymal transition in cancer. Pathol Oncol Res 23: 1-12, 2017.

12. Mohammadi A, Mansoori B and Baradaran B: The role of microRNAs in colorectal cancer. Biomed Pharmacother 84: 705-713, 2016.

13. Hovey AM, Devor EJ, Breheny PJ, Mott SL, Dai D, Thiel KW and Leslie KK: miR-888: A Novel cancer-testis antigen that targets the progesterone receptor in endometrial cancer. Transl Oncol 8: 85-96, 2015.

14. Lewis H, Lance R, Troyer D, Beydoun H, Hadley M, Orians J, Benzine T, Madric K, Semmes OJ, Drake R and Esquela-Kerscher A: miR-888 is an expressed prostatic secretions-derived microRNA that promotes prostate cell growth and migration. Cell Cycle 13: 227-239, 2014.

15. Huang S and Chen L: MiR-888 regulates side population properties and cancer metastasis in breast cancer cells. Biochem Biophys Res Commun 450: 1234-1240, 2014.

16. Bader AG: miR-888: Hit it when you see it! Cell Cycle 13: 351 , 2014.

17. Huang S, Cai M, Zheng Y, Zhou L, Wang Q and Chen L: miR-888 in MCF-7 side population sphere cells directly targets E-cadherin. J Genet Genomics 41: 35-42, 2014.

18. Chen Z, Liu S, Tian L, Wu M, Ai F, Tang W, Zhao L, Ding J, Zhang L and Tang A: miR-124 and miR-506 inhibit colorectal cancer progression by targeting DNMT3B and DNMT1. Oncotarget 6: 38139-38150, 2015.

19. Cao ZG, Li JJ, Yao L, Huang YN, Liu YR, Hu X, Song CG and Shao ZM: High expression of microRNA-454 is associated with poor prognosis in triple-negative breast cancer. Oncotarget 7: 64900-64909, 2016
20. Shen J, Song G, An M, Li X, Wu N, Ruan K, Hu J and Hu R: The use of hollow mesoporous silica nanospheres to encapsulate bortezomib and improve efficacy for non-small cell lung cancer therapy. Biomaterials 35: 316-326, 2014

21. Duff EK and Clarke AR: Smad4 (DPC4)-a potent tumour suppressor? Br J Cancer 78: 1615-1619, 1998.

22. Demagny H and De Robertis EM: Smad4/DPC4: A barrier against tumor progression driven by RTK/Ras/Erk and Wnt/GSK3 signaling. Mol Cell Oncol 3: e989133, 2016.

23. Weng M, Wu D, Yang C, Peng H, Wang G, Wang T and Li X: Noncoding RNAs in the development, diagnosis, and prognosis of colorectal cancer. Transl Res 181: 108-120, 2017.

24. Sinicrope FA, Okamoto K, Kasi PM and Kawakami H: Molecular biomarkers in the personalized treatment of colorectal cancer. Clin Gastroenterol Hepatol 14: 651-658, 2016.

25. Marrero JA and Lok AS: Newer markers for hepatocellular carcinoma. Gastroenterology 127 (5 Suppl 1): S113-S119, 2004.

26. Heneghan HM, Miller N and Kerin MJ: MiRNAs as biomarkers and therapeutic targets in cancer. Curr Opin Pharmacol 10: 543-550, 2010.

27. Wang J, Du Y, Liu X, Cho WC and Yang Y: MicroRNAs as regulator of signaling networks in metastatic colon cancer. Biomed Res Int 2015: 823620, 2015.

28. Zhang Q, Yu N and Lee C: Vicious cycle of TGF- $\beta$ signaling in tumor progression and metastasis. Am J Clin Exp Urol 2: 149-155, 2014.

29. Drabsch Y and ten Dijke P: TGF- $\beta$ signalling and its role in cancer progression and metastasis. Cancer Metastasis Rev 31: 553-568, 2012.

30. Matsuzaki K, Seki T and Okazaki K: TGF- $\beta$ signal shifting between tumor suppression and fibro-carcinogenesis in human chronic liver diseases. J Gastroenterol 49: 971-981, 2014.

31. Inamoto S, Itatani $\mathrm{Y}$, Yamamoto $\mathrm{T}$, Minamiguchi S, Hirai $\mathrm{H}$, Iwamoto M, Hasegawa S, Taketo MM, Sakai Y and Kawada K: Loss of SMAD4 promotes colorectal cancer progression by accumulation of myeloid-derived suppressor cells through the CCL15-CCR1 Chemokine Axis. Clin Cancer Res 22: 492-501, 2016.

32. Fleming NI, Jorissen RN, Mouradov D, Christie M, Sakthianandeswaren A, Palmieri M, Day F, Li S, Tsui C, Lipton L, et al: SMAD2, SMAD3 and SMAD4 mutations in colorectal cancer. Cancer Res 73: 725-735, 2013.

33. Singh S, Narang AS and Mahato RI: Subcellular fate and off-target effects of siRNA, shRNA and miRNA. Pharm Res 28: 2996-3015, 2011

34. Jackson AL and Linsley PS: Recognizing and avoiding siRNA off-target effects for target identification and therapeutic application. Nat Rev Drug Discov 9: 57-67, 2010

35. Serrano-Gomez SJ, Maziveyi M and Alahari SK: Regulation of epithelial-mesenchymal transition through epigenetic and post-translational modifications. Mol Cancer 15: 18, 2016.

36. Steinestel K, Eder S, Schrader AJ and Steinestel J: Clinical significance of epithelial-mesenchymal transition. Clin Transl Med 3: 17, 2014.

37. Saitoh M: Epithelial-mesenchymal transition is regulated at post-transcriptional levels by transforming growth factor- $\beta$ signaling during tumor progression. Cancer Sci 106: 481-488, 2015.

38. Katsuno Y, Lamouille S and Derynck R: TGF- $\beta$ signaling and epithelial-mesenchymal transition in cancer progression. Curr Opin Oncol 25: 76-84, 2013.

39. Shah PP and Kakar SS: Pituitary tumor transforming gene induces epithelial to mesenchymal transition by regulation of Twist, Snail, Slug, and E-cadherin. Cancer Lett 311: 66-76, 2011.

This work is licensed under a Creative Commons Attribution-NonCommercial-NoDerivatives 4.0 International (CC BY-NC-ND 4.0) License. 